\section{Bonding Effectiveness of Universal Adhesive to Intracoronal Bleached Dentin Treated with Sodium Ascorbate}

Thaís Fantinato Trindade, Luana Kelle Batista Moura, Walter Raucci Neto, Danielle Cristine Furtado Messias, Vivian Colucci
Department of Dentistry, Dental School, UNAERP Universidade de Ribeirão Preto, Ribeirão Preto, SP, Brazil

Correspondence: Profa. Dra. Vivian Colucci, Rua do Professor, 600, Jd. São Luiz, 14020-280 Ribeirão Preto, SP, Brasil. Tel.: +55-16-3603-6763. e-mail: vi.colucci@gmail.com

\begin{abstract}
This study evaluated the effect of restorative protocol with sodium ascorbate on the shear bond strength (SBS) of a universal adhesive to intracoronal bleached dentin. One hundred-and-twenty bovine dentin fragments were randomly divided into 12 groups $(n=10)$, according to the bleaching procedure (unbleached and bleached) and restorative protocol (no treatment, 10\% sodium ascorbate -10SA, 35\% sodium ascorbate -35SA and two-step etch-and-rinse -ER or one-step self-etch -SE Scotchbond universal adhesive approaches). Four whitening sessions were performed using 35\% hydrogen peroxide. The samples from control groups were kept in relative humidity at $37^{\circ} \mathrm{C}$. Immediately after bleaching procedures, the assigned antioxidant solution was applied on dentin and restorative procedures were performed following either the ER or the SE approach. After $24 \mathrm{~h}$, the specimens were subjected to SBS test. Data (MPa) were analyzed by ANOVA and Tukey's test $(\alpha=0.05)$. Lower SBS values were found for bleached specimens (8.54 $\mathrm{MPa})$ compared with those unbleached $(12.13 \mathrm{MPa})(\mathrm{p}<0.05)$. The bond strength of the sodium ascorbate-treated groups was higher than those untreated, regardless of the strategy employed $(p<0.05)$. Groups restored without sodium ascorbate showed lower bond strength values for both ER (8.32 MPa) and SE (8.28 MPa) adhesive strategies. The group treated with $10 \mathrm{SA}$ submitted to ER approach (10.14 MPa) was similar to untreated groups ( $p>0.05$ ). It may be concluded that bond strength of composite resin to intracoronal dentin was affected by restorative protocol and reduced by bleaching.
\end{abstract}

Key Words: tooth bleaching, adhesiveness, dentin.

\section{Introduction}

The color change of endodontically treated teeth is a fairly common condition in the dental clinic. Many therapies have been proposed aiming to restore aesthetics to discolored teeth. Among them, tooth whitening with hydrogen peroxide-based agents has been pointed out as an effective and more conservative method, compared to invasive interventions like prosthetic crowns, indirect veneers or even direct composite resin restorations (1), which involve wear of tooth structure to achieve satisfactory aesthetics.

Since the catalysis of most bleaching agents produces hydrogen peroxide, this is the main chemical responsible for the process (2). In bleaching procedure, reactive oxygen from hydrogen peroxide diffuses through the dentinal tubules and oxides the pigments, which absorb less light (3).

Placement of an adhesive restoration in the coronal access after completion of internal bleaching protects the endodontic treatment (4) and prevents microleakage (5). The quality of coronal restoration and endodontic treatment are equally important and they are strong independent predictors of the periapical status (4). However, reduced bond strength has been associated to bleached teeth (6), which can lead to early failure of the coronal restoration.
In order to minimize this problem, a waiting time between bleaching procedure and restorative treatment has been proposed (6). However, waiting to perform definitive restoration in non-vital bleached teeth is a critical condition, since these teeth present considerable structural loss and the additional bleaching procedure promotes changes in dentin organic content (7) turning them more susceptible to fracture (8). Moreover, endodontically treated teeth, submitted to bleaching and sealed with provisional restoration present higher fracture rates, but they return to normal after definitive restoration with composite resin (8).

Thus, seeking alternatives that can allow immediate restoration of endodontically treated teeth subjected to bleaching appears to be quite important. Studies have reported use of antioxidants such as sodium ascorbate, in order to enable immediate restoration of teeth subjected to bleaching. Evaluation of 10\% sodium ascorbate application in dentin submitted to bleaching with $35 \%$ hydrogen peroxide is scarce and contradictory.

Although Kaya and Türkün (9) demonstrated improved adhesion between composite resin and bleached dentin after application of 10\% sodium ascorbate, Briso et al. (10) failed to show enhanced bond strength when the adhesive protocol was performed immediately after 
bleaching. Additionally, it was shown that sodium ascorbate concentration should be proportional to the one used for bleaching (11). In other words, when hydrogen peroxide is used at $35 \%$, similar concentration of sodium ascorbate must be employed for effective removal of oxygen from the dental tissue $(2,11)$. Nevertheless, little is known about immediate bond strength of composite resin to bleached dentin subjected to the application of $35 \%$ sodium ascorbate.

Currently, the evolution of dental adhesive technology has become widespread and seeks to promote simplification of the technique associated with an effective and durable bonding (12), both in enamel and dentin.

Universal or multi-mode adhesive systems were introduced in Dentistry in order to allow that the same monomer solution be used for 2-step etch-and-rinse (ER) and single-step self-etch (SE) adhesive approaches. According to the manufacturers, these products can be used reliably in selective-enamel etch mode, in total-etch strategy to dentin and enamel or in self-etch mode to dentin, making them more attractive to the clinician and reducing the sensitivity of the application technique (13).

At this point, it is not clear whether these materials are effective for adhesion of composite resin to bleached dentin, combined or not with sodium ascorbate. The null hypothesis was that there would be no significant differences in bond strength of the bleached and unbleached dentin, independent of the surface treatment and the used universal adhesive approach.

\section{Material and Methods}

Prior to conducting the experiment, a pilot study was carried out to obtain the mean and standard deviation of the groups, aiming to calculate the sample size. The parameters for this calculation were: 0.05 significance level and 0.8 for the power test, using $G^{*}$ Power 3.1 statistical power analysis software (Heinrich Heine University, Düsseldorf, Germany) .

Sixty bovine incisors, stored in $0.1 \%$ thymol at 4 ${ }^{\circ} \mathrm{C}$, were selected and examined by stereomicroscopy (Leica Microsystems $\mathrm{GmbH}$, Wetzlar, Germany) with 20x magnification to discard those with fractures or cracks in the crown. All teeth were sectioned on the cement-enamel junction with a diamond disk (15HC, Buehler, Lake Bluff, IL, USA) using a sectioning machine (Isomet 1000; Buehler). Each crown produced two quadrangular intracoronal dentin slabs measuring $5 \times 5 \mathrm{~mm}, 120$ specimens in all.

The slabs were individually embedded in polyester resin (TDV, São Paulo, SP, Brazil) using polyvinyl chloride (PVC) cylinders $(2.0 \mathrm{~cm}$ diameter and $1.5 \mathrm{~cm}$ high), with the intracoronal dentin surfaces facing upwards. After resin polymerization, the specimens were planned and ground with a water-cooled polishing machine (Phoenix $\beta$, Buehler) using 180,400, 600 and 1200-grit $\mathrm{Al}_{2} \mathrm{O}_{3}$ papers.

The specimens were randomly assigned to 12 groups $(n=10)$ : I- unbleached + no treatment + ER, II- unbleached + no treatment $+\mathrm{SE}$, III- unbleached $+10 \%$ sodium ascorbate + ER, IV- unbleached $+10 \%$ sodium ascorbate $+\mathrm{SE}_{1} \mathrm{~V}$ unbleached $+35 \%$ sodium ascorbate $+E R, \mathrm{VI}$ - unbleached $+35 \%$ sodium ascorbate $+\mathrm{SE}, \mathrm{VII}$ - bleached + no treatment + ER, VIII- bleached + no treatment $+\mathrm{SE}_{1} \mathrm{IX}$ - bleached + $10 \%$ sodium ascorbate $+E R, X$ - bleached $+10 \%$ sodium ascorbate $+\mathrm{SE}_{1} \mathrm{XI}$ - bleached $+35 \%$ sodium ascorbate + $E R, X I I-$ bleached $+35 \%$ sodium ascorbate + SE. Material composition and manufacturers are summarized in Table 1.

Specimens from the bleached groups were subjected to four whitening sessions, using 35\% hydrogen peroxide (Whiteness HP Maxx, FGM Produtos Odontológicos Ltda, Joinvile, SC, Brazil). A layer about $1.0 \mathrm{~mm}$ thick $(0.2 \mathrm{~g})$ of bleaching agent was applied on dentin surface for $15 \mathrm{~min}$ and after this the surface was washed with $5 \mathrm{~mL}$ distilled

Table 1. Composition of the materials

\begin{tabular}{|c|c|c|}
\hline Material type and brand & Composition & Manufacturer \\
\hline Bleaching agent (Whiteness HP Maxx) & $\begin{array}{l}\text { After mixture of the phases: hydrogen peroxide } \\
\text { at 35\%, thickeners, dye mixture, glycol, } \\
\text { inorganic load and deionized water }\end{array}$ & $\begin{array}{l}\text { FGM - Dental Products, } \\
\text { Joinvile, SC, Brazil }\end{array}$ \\
\hline Antioxidant solution (10\% sodium ascorbate) & Sodium ascorbate and osmolality water & $\begin{array}{l}\text { Bioquanti, Ribeirão } \\
\text { Preto, SP, Brazil }\end{array}$ \\
\hline Antioxidant solution ( $35 \%$ sodium ascorbate) & Sodium ascorbate and osmolality water & $\begin{array}{l}\text { Bioquanti, Ribeirão } \\
\text { Preto, SP, Brazil }\end{array}$ \\
\hline Etching gel (Scotchbond Universal Etchant) & $35 \%$ phosphoric acid & $\begin{array}{l}\text { 3M/ESPE, St. } \\
\text { Paul, MN, USA }\end{array}$ \\
\hline $\begin{array}{l}\text { Adhesive System (Scotchbond } \\
\text { Universal Adhesive) }\end{array}$ & $\begin{array}{l}\text { MDP phosphate monomer, dimethacrylate resins, HEMA, } \\
\text { Vitrebond copolymer, filler, ethanol, water, initiators, silane }\end{array}$ & $\begin{array}{l}\text { 3M Deutschland GmbH, } \\
\text { Seefeld, Germany }\end{array}$ \\
\hline Composite resin (Filtek Z-250) & $\begin{array}{l}\text { UDMA (urethane dimethacrylate), Bis-EMA (bisphenol } \\
\text { A polyethylene glycol diether dimethacrylate), TEGDMA } \\
\text { (tri-ethylene glycol dimethacrylate) and inorganic filler }\end{array}$ & $\begin{array}{l}\text { 3M/ESPE, St. } \\
\text { Paul, MN, USA }\end{array}$ \\
\hline
\end{tabular}


water. Three applications of the bleaching product were made in each session, as described above. After each bleaching session, specimens were kept in relative humidity at $37^{\circ} \mathrm{C}$ for seven days, until next session.

Slabs from the groups treated with sodium ascorbate (Bioquanti, Ribeirão Preto, SP, Brazil), regardless their concentration, had the respective antioxidant solution applied on dentin surface immediately after the bleaching procedure. An aliquot of $600 \mu \mathrm{L}$ ascorbate solution was dropped on dentin for 1 min under agitation with a microbrush. Afterwards, the surface was washed with water and another application of sodium ascorbate was made as previously described. The specimens were rinsed with distilled water and bonding procedures were performed immediately. Specimens from control groups were kept in relative humidity at $37^{\circ} \mathrm{C}$.

Specimens from groups in which universal adhesive was applied with 2-step etch-and-rinse strategy were etched with $35 \%$ phosphoric acid (3M/ESPE, St Paul, MN, USA) for $15 \mathrm{~s}$, washed with distilled water for $15 \mathrm{~s}$ and dried with absorbing paper.

All specimens received two layers of Scotchbond Universal adhesive (3M Deutschland $\mathrm{GmbH}$, Seefeld,
Germany), followed by an air spray and then were lightcured for $10 \mathrm{~s}$ using a photo-curing unit (Radii Plus, SDI North America Inc., Bensenville, IL, USA) according to the manufacturer's instructions.

Specimens were restored with Z-250 composite resin (3M/ESPE) using a stabilized split Teflon mold ( $3 \mathrm{~mm}$ inner diameter, $4 \mathrm{~mm}$ high), in order to obtain restorative material cylinders with the above described measurements.

After 24-hour water storage at $37^{\circ} \mathrm{C}$, the specimens were fixed in the universal testing machine (MEM-2000, EMIC, São José dos Pinhais, PR, Brazil) and tested with a $500 \mathrm{~N}$ load cell at a speed of $0.5 \mathrm{~mm} / \mathrm{min}$ until failure. A schematic illustration presenting the experimental design of the shear bond strength test is shown in Figure 1.

The fractured specimens were observed with 80x magnification using a stereomicroscope (Leica S6D Stereozoom, Leica Mycrosystems AG, Switzerland) to assess the failure modes, which were classified as adhesive if occurred at the substrate/adhesive interface, cohesive if occurred in the material or the substrate and mixed if involved both the interface and material (Fig. 2).

Data obtained in shear bond test were submitted to statistical analysis. After checking homoscedasticity

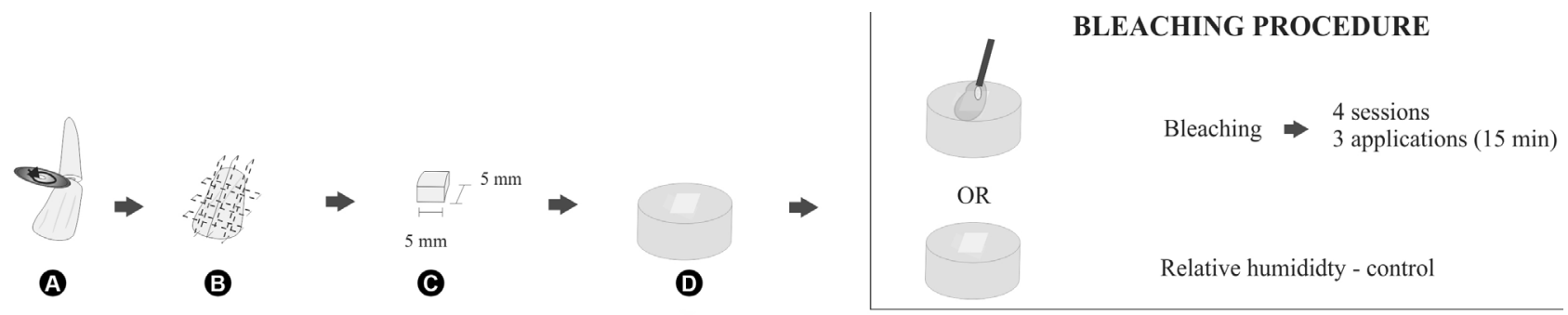

()
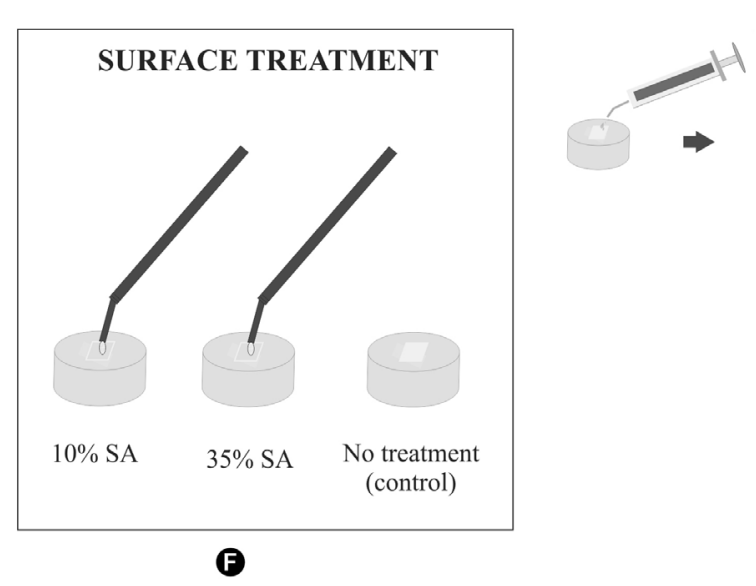

$35 \%$ phosporic acid

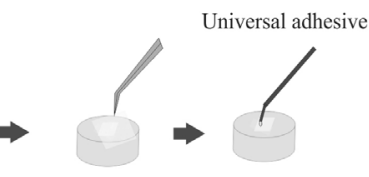

OR

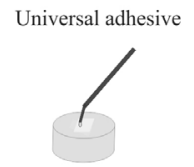

Etch-and-rinse approach

Self-etch

$\boldsymbol{\Theta}$ approach

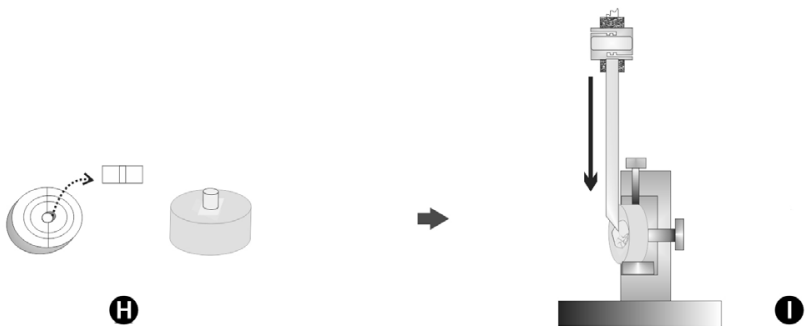

Figure 1: Schematic illustration. The roots were removed from bovine incisors (A), crowns (B) were sectioned into $5 \times 5$ mm specimens (C), which were included into acrylic resin and ground to plane intracoronal dentin (D). Sixty specimens were subjected to bleaching procedure and the other 60 were maintained in relative humidity (E). Immediately after bleaching, specimens were treated with SA (F) and the bonding procedures were performed after either ER or SE approaches (G). Next, the resin composite restorations were made (H) and the specimens were loaded in tension (I). 
with Bartlet's test and normality with Shapiro Wilk's test $(p=0.24108)$, ANOVA (power test $=86.4 \%)$ and Tukey's test were employed $(\alpha=0.05)$. The statistical analysis was performed with the Assistat 7.7 beta software (Federal University of Campina Grande, PB, Brazil). Bond failure was analyzed qualitatively.

\section{Results}

Triple interaction, interaction between surface treatment and bleaching, and interaction between adhesive approaches and bleaching were not significant ( $p>0.05)$. Interaction between surface treatment and adhesive strategies was statistically significant $(p<0.05)$. Groups restored without sodium ascorbate showed lower bond strength values for both ER (8.32 MPa) and SE (8.28 MPa) adhesive strategies ( $p>0.05$ ). The bond strength of the sodium ascorbate-treated groups was higher than those untreated, regardless the employed strategy $(p<0.05)$. The group treated with 10SA submitted to ER approach (10.14 MPa) was similar to the untreated group ( $p>0.05$ ). The shear bond strength means according to restorative

\begin{tabular}{|c|c|c|}
\hline \multirow{2}{*}{ Surface treatment } & \multicolumn{2}{|c|}{ Universal Adhesive approach } \\
\hline & Etch-and-rinse & Self-etch \\
\hline No treatment & $8.32(1.83) \mathrm{Ba}$ & $8.28(2.25) \mathrm{Ba}$ \\
\hline $10 \%$ Sodium ascorbate & 10.14 (3.32) $\mathrm{ABa}$ & 11.51(1.67) Aa \\
\hline $35 \%$ Sodium ascorbate & $11.85(1.76) \mathrm{Aa}$ & $11.90(1.29) \mathrm{Aa}$ \\
\hline
\end{tabular}

Different uppercase letters in columns and lowercase letters in rows indicate statistically significant difference $(p<0.05)$. protocols are in Table 2. Significant effects were found for bleaching $(p<0.05)$. Lower shear bond strength values were found for bleached specimens ( $8.54 \mathrm{MPa}$ ) compared with the unbleached $(12.13 \mathrm{MPa})(\mathrm{p}<0.05)$.

The analysis of failure after the shear bond test revealed that the adhesive failure mode was predominantly observed in the bleached specimens. Unbleached groups showed homogeneous distribution of failure modes. Figure 2 shows the fracture pattern distribution of the specimens.

\section{Discussion}

Various mechanical test methods, such as shear and tensile bond strength tests have been commonly used to evaluate bonding of dental adhesives to enamel and dentin (14). Among the used tests, each of them has both advantages and limitations. Shear bond strength tests have been widely employed, mainly because of their relative simplicity if compared with microtensile bond strength tests, which employ specimens with a smaller bonding area aiming to decrease no uniform stress distribution at the adhesive interface (15). In the shear bond test, stresses may be mostly concentrated in the dentin or composite resin, leading them to fail before the adhesive interface itself (15). However, despite the shear technique producing lower bond strength values than the microtensile test, both results are highly correlated and they provide similar values of bond strength between adhesive system and dentin (14).

Based on the results of this study, bleaching had a significant effect on the immediate bond strength between composite resin and intracoronal dentin. Bleaching procedure makes the hybrid layer between resin monomers and collagen fibrils more instable and it has been associated to decrease in bond strength between composite resin and dentin. When the adhesive procedures were conducted immediately after bleaching, the reactive oxygen, a highly reactive chemical in the dentin structure after bleaching, hinders penetration and inhibits the polymerization of the adhesive system and reduces the strength of the interface formed between the dentin and restorative material (6). Additionally, a reduced hybrid layer and resin tag formation was reported when the adhesive procedures were performed on bleached dentin (10). Besides the effect of the reactive oxygen radicals in the dentin tubules,
Figure 2. Fracture pattern distribution of the specimens in the groups. Sodium ascorbate (SA); Etchand-rinse approach (ER); Self-etch approach (SE). 
bleaching agents may change the organic dentin matrix (16), compromising diffusion of the adhesive system through the interfibrillar spaces into the collagen network, since an effective dentin bonding depends on the structural integrity of fibrillar type I collagen (17). These facts could explain the predominance of adhesive fracture pattern in the bleached groups in this study.

Adhesion to dentinal substrate is generally very difficult due to its organic, hydrophilic and structural nature (18). Additionally, the composition, structure and morphology vary from superficial to deep dentin (19), where there are fewer collagen fibrils (20) and a higher number of tubules, which increase dentin wetness, making adhesion to deeper dentin more difficult than to superficial dentin (21).

Since the effectiveness of the adhesion to dentin depends on the structural stability of the hybrid layer formed between resin monomers and collagen network (22), some strategies have been proposed aiming to improve adhesion.

In the present study the use of sodium ascorbate, regardless its concentration was able to enhance the immediate bond strength between composite resin and intracoronal dentin. Sodium ascorbate presents low toxicity and has a neutral pH (approximately 7), being appropriate for use on dental structures without producing undesirable damages (23). The reaction between SA and oxygen into dentin peaks within $1 \mathrm{~min}$ and thereafter the reaction reduces considerably (2). Therefore, in this study, sodium ascorbate at both concentrations was applied with two applications for one minute each $(11,24)$. Additionally, the SA in solution form was chosen to conduct this study. Other authors (25) found that both hydrogel and solution forms of sodium ascorbate may equally improve the reduced bond strength of resin composite to dental tissue subsequent to a bleaching procedure.

Sodium ascorbate reacts with free radicals, such as oxygen generated by the degradation of hydrogen peroxide during bleaching, neutralizing them in the structure where they are entrapped (9). Additionally, SA acts in the synthesis of hydroxyproline and hydroxylysine in collagen, stabilizing the collagen triple helix, improving the formation of intermolecular cross-links in collagen (21), which enhances the bond strength and its durability.

According to Kaya and Turkun (9), 10\% sodium ascorbate improved immediate bond strength between composite resin and bleached dentin, which is in agreement with results obtained in this study. Antioxidant solutions, in both studies, were shaken on the dentin surface. Briso et al. (10) used 10\% sodium ascorbate in a passive manner for $10 \mathrm{~min}$ and have failed to show improved bonding between restorative material and dentin. Stirring the sodium ascorbate may have favored the removal of oxygen.
In another study (24), 35\% sodium ascorbate was not able to increase bond strength, which disagrees with the results obtained in this study. Some considerations should be made when comparing these studies. In the current study, four bleaching sessions were conducted with 3 applications of 15 min each with 7-day intervals between them, simulating the in-office bleaching technique. Instead, Hansen et al. (24) employed 35\% hydrogen peroxide for 7 consecutive days, simulating the walking-bleaching technique. Since diffusion of the bleaching agent is proportional to the exposure time (3), this fact could explain the divergent results.

The Universal adhesives have been developed aiming to facilitate the bonding technique and to improve the adhesion to dental substrates under different clinical conditions. During the procedure of selective acid etching on enamel, which is still recommended for the Universal adhesives, accidental etching of dentin may occur (12). However, in order to confirm the possibility of the "universal adhesion", the different etching approaches should not interfere in the bond strength (12). In this study, in dentin substrate not treated with sodium ascorbate or treated with 35\% sodium ascorbate, phosphoric acid did not affect the adhesive strength. Some previous studies $(12,13,26)$ found that the etching step prior to application of the Scotchbond universal adhesive did not interfere with immediate bond strength. The Scotchbond Universal presents MDP in its composition which has been shown to bond ionically to hydroxyapatite by nano-layering (27), making it less susceptible to the presence or absence of moisture. According to the manufacturer, another compound of Scotchbond Universal, the methacrylatemodified polyalkenoic acid copolymer, incorporated into the adhesive along with optimized ratios of HEMA and water, provides for a more consistent bond performance to dentin under wet and dry conditions.

Although the immediate bond strength did not decrease initially, studies that evaluated longevity of bonding of universal adhesives to dentin in different etching modes showed that SE approach showed more stable bonds even after long-term water storage (26). The adhesive interface resulting from etch-and-rinse approach appeared to be ultra-structurally more vulnerable to biodegradation (28). Further studies are required to evaluate longevity of bond strength between universal adhesives and bleached dentin treated with sodium ascorbate over time.

\section{Resumo}

Este estudo avaliou o efeito do protocolo restaurador empregando ascorbato de sódio na resistência ao cisalhamento do adesivo universal à dentina intracoronária clareada. Cento e vinte fragmentos de dentina bovina foram aleatoriamente divididos em doze grupos $(n=10)$, de acordo com o procedimento clareador (clareados e não clareados) e protocolo 
restaurador (sem tratamento, ascorbato de sódio 10\% (10AS), ascorbato de sódio (35AS) e estratégia de condicionamento total de dois passos (ER) ou estratégia autocondicionante de um passo (SE) com o sistema adesivo Scotchbond universal. Quatro sessões de clareamento foram realizadas empregando peróxido de hidrogênio a $35 \%$. Os espécimes do grupo controle foram mantidos em umidade relativa a $37^{\circ} \mathrm{C}$. Imediatamente após os procedimentos de clareamento, as soluções antioxidantes selecionadas foram empregadas na dentina e os procedimentos restauradores foram realizados seguindo as estratégias ER ou SE. Após $24 \mathrm{~h}$, os espécimes foram submetidos ao teste de resistência ao cisalhamento. Os dados (MPa) foram analisados pela ANOVA e teste de Tukey $(\alpha=0,05)$. Os menores valores de resistência ao cisalhamento foram encontrados para os espécimes clareados $(8,54 \mathrm{MPa})$ comparados com aqueles não clareados $(12,13 \mathrm{MPa})(\mathrm{p}<0,05)$. A resistência de união dos grupos tratados com ascorbato de sódio foi maior que aqueles não tratados $(p<0,05)$, independentemente da estratégia empregada. Grupos restaurados sem ascorbato de sódio demonstraram menores valores de resistência de união para ambas as estratégias adesivas ER $(8,32 \mathrm{MPa})$ e SE $(8,28 \mathrm{MPa})(\mathrm{p}<0,05)$. 0 grupo tratado com ascorbato de sódio a 10\% submetido à estratégia ER $(10,14 \mathrm{MPa})$ foi similar ao não tratado $(p>0,05)$. Pode ser concluido que a resistência de união da resina composta à dentina intracoronária foi afetada pelo protocolo restaurador e reduzida pelo clareamento.

\section{References}

1. Sari $T$, Celik G, Usumez A. Temperature rise in pulp and gel during laseractivated bleaching: in vitro. Lasers Med Sci 2015;30:577-582.

2. Freire $A$, Durski MT, Ingberman $M$, Nakao LS, Souza EM, Vieira $S$. Assessing the use of 35 percent sodium ascorbate for removal of residual hydrogen peroxide after in-office tooth bleaching. JADA 2011;142:836-841.

3. Joiner A. The bleaching of teeth: a review of the literature. J Dent. 2006;34:412-419.

4. Song M, Park M, Lee CY, Kim E. Periapical status related to the quality of coronal restorations and root fillings in a Korean population. J Endod 2014:40:182-186.

5. Türkün M, Türkün LS. Effect of nonvital bleaching with 10 percent carbamide peroxide on sealing ability of resin composite restorations. Int Endod J 2004;37:52-60.

6. Shinohara MS, Peris AR, Pimenta LA, Ambrosano GM. Shear bond strength evaluation of composite resin on enamel and dentin after nonvital bleaching. J Esthet Restor Dent 2005;17:22-29.

7. Azevedo RA, Silva-Sousa YTC, Souza-Gabriel AE, Messias DC, Alfredo E, Silva RG. Fracture resistance of teeth subjected to internal bleaching and restored with different procedures. Braz Dent J 2011;22:117-121.

8. Roberto $A R$, Sousa-Neto MD, Vapiana R, Giovani $A R$, Souza Filho $C B$, Paulino SM, et al.. Effect of different restorative procedures on the fracture resistance of teeth submitted to internal bleaching. Braz Oral Res 2012;26:77-82.

9. Kaya $A D$, Türkun M. Reversal of dentin bonding to bleached teeth. Oper Dent 2003;28:825-829.

10. Briso ALF, Rahal V, Sundfeld RH, Santos PH, Alexandre RS. Effect of sodium ascorbate on dentin bonding after two bleaching techniques. Oper Dent 2014;39:195-203.
11. Freire A, Sousa EM, Menezes-Caldas DB, Rosa EA, Bordin CF, de Carvalho $\mathrm{RM}$, et al.. Reaction kinetics of sodium ascorbate and dental bleaching. J Dent 2009;37:932-936

12. Wagner $A$, Wendler $M$, Petschelt $A$, Belli $R$, Lohbauer U. Bonding performance of universal adhesives in different etching modes. J Dent 2014;42:800-807.

13. Muñoz MA, Luque $I$, Hass $V$, Reis $A$, Loguercio $A D$, Bombarda $N H$. Immediate bonding properties of universal adhesives to dentine. J Dent 2013;41:404-411.

14. Pinzon LM, Watanabe LG, Reis AF, Powers JM, Marshall SJ, Marshall $\mathrm{GW}$. Analysis of interfacial structure and bond strength of self-etch adhesive systems. Am J Dent 2013;26:335-340.

15. Placido E, Meira JBC, Lima RG, Muench A, Souza RM, Ballester RY. Shear versus micro-shear bond strength test: A finite elements stress analysis. Dent Mater 2007;23:1086-1092.

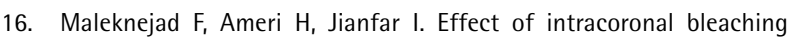
agents on ultrastructure and mineral content of dentin. J Conserv Dent 2012;15:174-177.

17. Pereira PN, Bedran-de-Castro AK, Duarte WR, Yamauchi M. Removal of noncollagenous components affects dentin bonding. J Biomed Mater Res B: Appl Biomater 2007;80:86-91.

18. Miyazaki M, Tsujimoto A, Tsubota K, Takamizawa T, Kurokawa H, Platt JA. Important compositional characteristics in the clinical use of adhesive systems. J Oral Sci 2014;56:1-9.

19. Marshall GW, Marshall SJ, Kenny JH, Balooch M. The dentin substrate: Structure and properties related to bonding. J Dent 1997;25:441-458.

20. Srinivasulu S, Vidhya S, Sujatha M, Mahalaxmi S. Shear bond strength of composite to deep dentin after treatment with two different crosslinking agents varying time intervals. Oper Dent 2012;37:485-491.

21. Perdigão J. Dentin bonding - Variables related to the clinical situation and the substrate treatment. Dent Mater 2010;26:e24-e37.

22. Macedo GV, Uamauchi M, Bedran-Russo AKB. Effects of chemical crosslinkers on caries affected dentin bonding. J Dent Res 2009;88:10961100.

23. Lai SC, Mak YF, Cheung GS, Osorio R, Toledano M, Carvalho RM, et al.. Reversal of compromised bonding to oxidized etched dentin. J Dent Res 2001;80:1919-1924.

24. Hansen JR, Frick KJ, Walker MP. Effect of 35\% sodium ascorbate treatment on microtensile bond strength after nonvital bleaching. J Endod 2014;40:1668-1670.

25. Kimyai S, Valizadeh H. Comparison of the effect of hydrogel and solution of sodium ascorbate on dentin-composite bond strength after bleaching. J Contemp Dent Pract 2008;9:105-112.

26. Muñoz MA, Loque-Martinez I, Malaquias $P$, Hass V, Reis A, Campanha $\mathrm{N}$, et al.. In vitro longevity of bonding properties of universal adhesives to dentin. Oper Dent 2015;40:282-292.

27. Yoshida Y, Yoshihara K, Nagaoka N, Hayakawa S, Torii Y, Ogawa T, et al.. Self-assembled nano-layering at the adhesive interface. J Dent Res 2012;91:376-381.

28. Hanabusa M, Mine A, Kuboki T, Momoi Y, Van Ende A, Van Meerbeek B, et al.. Bonding effectiveness of a new 'multi-mode' adhesive to enamel and dentine. J Dent. 2012;40:475-484.

Received November 18, 2015 Accepted April 4, 2016 